\title{
The relationship between physical activity and mental health varies across activity intensity levels and dimensions of mental health among women and men
}

\author{
Melinda Asztalos*, Ilse De Bourdeaudhuii and Greet Cardon \\ Department of Movement and Sports Sciences, Ghent University, Watersportlaan 2, B-9000 Gent, Belgium
}

Submitted 23 January 2009: Accepted 5 November 2009: First published online 17 December 2009

\begin{abstract}
Objective: To explore gender-specific variations related to activity intensity in the relationship between physical activity (PA) and mental health $(\mathrm{MH})$. Evaluating whether psychological well-being enhances with increases in PA at recommended levels and above, in the general population.

Design: Cross-sectional.

Setting: Population-based, representative for Belgium.

Subjects: A total of 6803 adults aged 25-64 years from the Belgian National Health Interview Survey.

Results: Multiple logistic regression analyses showed that clearly different intensity levels characterised the PA that associated with MH in women and men. In men, inverse associations existed between participation in vigorous-intensity PA and feelings of depression ( $\mathrm{OR}=0.580 ; 95 \%$ CI $0 \cdot 405,0 \cdot 830)$, anxiety (OR $=0.547$; $95 \%$ CI $0 \cdot 364,0 \cdot 821)$ and symptoms of somatisation (OR $=0 \cdot 590 ; 95 \%$ CI 0.398, $0 \cdot 874)$. In women, positive associations existed between walking and emotional well-being $(\mathrm{OR}=1 \cdot 202 ; 95 \% \mathrm{CI} 1 \cdot 038,1 \cdot 394)$ and inverse associations between participation in moderate-intensity $\mathrm{PA}$ and symptoms of somatisation $(\mathrm{OR}=$ $0.737 ; 95 \%$ CI $0.556,0.977)$. Secondary analyses confirmed that differences in psychological complaints were significant for vigorous PA in men, and for moderate PA in women, whereas differences in emotional well-being were significant for walking exclusively in women.

Conclusions: In the general population, the PA-MH relationship is always positive, regardless of activity intensity. In men, it addresses complaints (symptoms, palpable discomfort) and the optimal PA intensity is high. In women, it addresses complaints, but also distress (lowered mood, disturbing anxiety, altered wellbeing) and the PA intensity is mild.
\end{abstract}

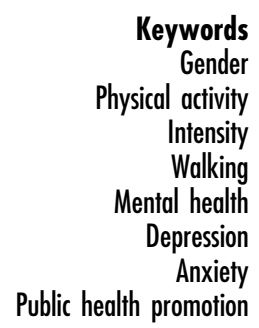

Physical activity (PA) recommendations do not differentiate between health outcomes associated with PA, namely its physical health benefits and its mental health $(\mathrm{MH})$ benefits. Updated guidelines simply note that for promoting and maintaining health, all healthy adults aged 18-65 years need moderate-intensity aerobic PA for a minimum of $30 \mathrm{~min}$ on $5 \mathrm{~d}$ each week, or vigorousintensity aerobic PA for a minimum of 20 min on $3 \mathrm{~d}$ each week $^{(1)}$. Earlier recommendations from the Centers for Disease Control and Prevention (2000) included walking as well, for at least $30 \mathrm{~min}$ on $4 \mathrm{~d}$ each week, at approximately moderate pace ${ }^{(2)}$. Because of this lack of specificity in the recommendations, insufficient attention is granted for the PA-MH relationship, and the value of PA in $\mathrm{MH}$ promotion is unsettled and underappreciated.

Other researchers have also emphasised that the $\mathrm{PA}-\mathrm{MH}$ relationship deserves special attention ${ }^{(4-7)}$, as it is much more complex than the relationship between PA and physical health ${ }^{(3)}$. Its great complexity manifests on three coordinates: (i) in terms of activity domains; hence, to date, research could not establish a threshold or an optimal intensity, type, frequency and duration of PA necessary to protect against $\mathrm{MH}$ problems or to improve $\mathrm{MH}$ status ${ }^{(16)}$; (ii) regarding possible responses, namely, different psychological conditions are likely to respond differently to alternative PA programmes ${ }^{(9,10)}$; and (iii) the $\mathrm{PA}-\mathrm{MH}$ relationship is likely to vary depending on individual characteristics ${ }^{(21,34,35)}$; hence, in an ideal setting, virtually every individual should receive personalised PA recommendations. As this is not feasible, differentiations should be made at least between the major groups of individuals (e.g. among women and men).

Existing knowledge lines up overwhelming evidence of a definite positive relationship between $\mathrm{PA}$ and $\mathrm{MH}^{(15)}$, 
which manifested in both clinical and general populations. Findings associated PA with reduced depression and anxiety, improved sleep, elevated mood, better self-esteem ${ }^{(4)}$, enhanced physical self-perception, selfefficacy, cognitive functioning ${ }^{(5)}$, increased health-related quality of life ${ }^{(13)}$ and efficient stress prevention and reduction $^{(14)}$. Furthermore, the MH benefits of PA were recognised as being at least as important as the physical health benefits of $\mathrm{PA}^{(11)}$, and it was accented that PA not only has the potential to reduce morbidity and mortality from $\mathrm{MH}$ problems ${ }^{(8)}$ but also is cost-effective and provides additional physical health benefits ${ }^{(7)}$. Despite all this, it is still insufficiently acknowledged that a more differentiated picture about the PA-MH relationship could strengthen statements about it, granting PA an adequate recognition as an effective preventive measure for $\mathrm{MH}$ problems, or an effective coping mechanism for symptoms of stress and distress. Hence, producing a more differentiated picture about the $\mathrm{PA}-\mathrm{MH}$ relationship remains still a pressing necessity ${ }^{(3,12,15)}$.

With this aim, the present study focused on the issue of activity intensity in the PA-MH relationship, which has a complexity on its own, as earlier findings line up three rather disagreeing opinions: (i) pro vigorous-intensity; (ii) contra vigorous-intensity, favouring moderate- or light-intensity; and (iii) sustaining that intensity is not relevant in this relationship.

In the first group, studies including clinical populations found that vigorous PA was most effective in reducing depression $^{(17)}$, and resulted in anxiolytic effects comparable in magnitude to the anxiolytic effects of milder exercises, but only 10-15 min later, following short-lived anxiety elevations immediately post-exercise ${ }^{(18)}$. Compared with moderate-intensity activities, vigorous-intensity exercise resulted in the sharpest decline in state anxiety, but only 30 min post-exercise ${ }^{(19)}$. Further, the calculated anxiety reducing effect size for moderate and very high-intensity PA was found noticeably greater than the effect size for low- and moderate-to-vigorous-intensity $\mathrm{PA}^{(33)}$.

Researchers who conducted studies in general populations shared a different opinion. These advocated that a too strenuous PA regimen might lead to deleterious effects on $\mathrm{MH}$ in the general population ${ }^{(21)}$. Some stated that vigorous PA can become overly stressing, resulting in mental fatigue, and subsequent fear, anxiety, anger and depression, especially in women ${ }^{(22,23)}$; others found that high-intensity PA is ineffective in managing anxiety in healthy individuals ${ }^{(20)}$. Hence, it was suggested that moderate-to-low-intensity PA is most beneficial for enhancing mood and improving psychological functioning ${ }^{(24)}$. Comparatively, moderate-intensity aerobic exercise was found most effective in reducing tension and anxiety, with lighter intensities being less effective, and higher intensities resulting in increased anxiety ${ }^{(25-27)}$. Accordingly, people who trained in moderate-intensity had greater psychological benefits than those who trained vigorously $^{(28)}$.
A third point of view shared by some researchers is that intensity might not be an important factor in the PA-MH relationship ${ }^{(29)}$; moreover, exercise might not even need to produce a physiological training effect in order to enhance psychological well-being and help managing feelings of depression and anxiety ${ }^{(30-32)}$.

These disagreeing positions call for a more differentiated explorative approach in analysing the PA-MH relationship, which is likely to vary across PA domains and $\mathrm{MH}$ dimensions, and in different categories of people. Hence, in one study, associations between PA and less anxiety and depression, higher positive mood and general well-being were strongest among women and those aged $40+$ years ${ }^{(34)}$. In another study, women experienced reductions in mood disturbance and improvements in general mood after a mild-intensity PA that included some cognitive elements (i.e. Tai Chi), whereas men reported increased positive affect following a more intense PA that had no cognitive components (i.e. brisk walking $65 \%-75 \%$ of maximum heart rate) ${ }^{(35)}$.

Consequently, in the present study, we analysed associations between PA of three different intensities, executed above and below the recommended levels, and five dimensions of $\mathrm{MH}$, four relating to $\mathrm{MH}$ problems commonly found in the general population (i.e. not psychiatric diagnoses, but psychological complaints, namely feelings of depression or anxiety, symptoms of somatisation and sleeping problems), and overall emotional well-being - in terms of good mood and manageable distress - as a fifth one. We asked whether emotional well-being enhances and whether psychological complaints decrease with increases in PA at recommended levels, and above, in a substantial population sample of 6803 adults. Our objective was to explore variations related to PA intensity, and we were particularly interested in creating a gender-specific picture about these relationships.

\section{Methods}

\section{Participants and design}

The Belgian Health Interview Survey (B-HIS) aims at giving a description of the health status of the Belgian population, specifically at identifying health problems, describing the health status and health needs of the population, estimating the prevalence and distribution of health indicators, and analysing social trends in health status. Hence, the Belgian Scientific Institute of Public Health contacted 12107 households, based on reference persons selected by the Belgian National Institute of Statistics from the National Registry. Whole households corresponding to reference persons were invited to participate in the survey. In large households, a maximum of four members could agree to participate in the survey, so that replication of certain health patterns, and thus contamination of the data by repetitive 
Table 1 Characteristics of the sample in terms of education and physical activity

\begin{tabular}{|c|c|c|c|c|c|c|}
\hline & \multicolumn{2}{|c|}{ Men } & \multicolumn{2}{|c|}{ Women } & \multicolumn{2}{|c|}{ Total sample } \\
\hline & $n$ & $\%$ & $n$ & $\%$ & $n$ & $\%$ \\
\hline & 3368 & $49 \cdot 5$ & 3435 & $50 \cdot 5$ & 6803 & 100 \\
\hline \multicolumn{7}{|c|}{ Socio-economic status (SES) } \\
\hline Professionals & 785 & $23 \cdot 3$ & 825 & $24 \cdot 0$ & 1610 & $23 \cdot 7$ \\
\hline Managers & 249 & $7 \cdot 4$ & 265 & $7 \cdot 7$ & 514 & $7 \cdot 6$ \\
\hline Clerks & 808 & $24 \cdot 0$ & 951 & $27 \cdot 7$ & 1759 & $25 \cdot 8$ \\
\hline Skilled workers & 1024 & $30 \cdot 4$ & 886 & $25 \cdot 8$ & 1910 & $28 \cdot 1$ \\
\hline Unskilled workers & 502 & $14 \cdot 9$ & 508 & $14 \cdot 8$ & 1010 & $14 \cdot 8$ \\
\hline Physical activity & & & & & & \\
\hline \multicolumn{7}{|c|}{ Recommended vigorous PA } \\
\hline Yes (>60 min/week) & 1405 & $42 \cdot 3$ & 830 & $24 \cdot 4$ & 2235 & $32 \cdot 8$ \\
\hline No (<60 min/week) & 1914 & $57 \cdot 7$ & 2571 & $75 \cdot 6$ & 4485 & 65.9 \\
\hline \multicolumn{7}{|c|}{ Recommended moderate PA } \\
\hline Yes (>150 min/week) & 1302 & $39 \cdot 2$ & 1114 & $32 \cdot 8$ & 2416 & $35 \cdot 5$ \\
\hline No (<150 min/week) & 2017 & $60 \cdot 8$ & 2287 & $67 \cdot 2$ & 4304 & $63 \cdot 3$ \\
\hline \multicolumn{7}{|l|}{ Recommended Walking } \\
\hline Yes (>120 min/week) & 1923 & $57 \cdot 9$ & 1954 & $57 \cdot 5$ & 3877 & $57 \cdot 0$ \\
\hline No (<120 min/week) & 1396 & $42 \cdot 1$ & 1447 & $42 \cdot 5$ & 2843 & $41 \cdot 8$ \\
\hline
\end{tabular}

PA, physical activity.

information, would be minimised. In all instances, the reference persons were included in the survey, if agreed to cooperate. First, invitation letters were sent to the households, attached to informative leaflets. Then, trained interviewers contacted the households' members and explained to them the objectives of the survey, obtaining their informed consent for cooperation.

The initial target sample size was 10000 participants, (i.e. 3500 participants for Flanders and Wallonia, respectively, plus 3000 participants for Brussels). Data collected from this number of people could provide a realistic picture of the health status of the entire population of Belgium. However, because of overrepresentation in four regions (i.e. Antwerp, Limburg, Luxemburg and Henegouwen), the final target sample size was established at 12050 participants. With a response rate of $61.4 \%$ at household level (i.e. 7434 households), the B-HIS has ultimately included a total of 10170 participants; 4971 men $(48 \cdot 9 \%)$ and 5198 women $(51 \cdot 1 \%)$. In $22 \cdot 1 \%$ of all contacted households, participation in the survey was refused due to lack of time; in $38.3 \%$ of households, members were not interested in the survey; in $6.7 \%$ of households, members claimed that they were too old and/or sick to participate in the survey; in 5.8\% of households, members had other reasons for refusal; and in $26.9 \%$ of households, members did not specify a reason for their refusal. Additional details about the sample are available on the website of the Epidemiology Unit of the Belgian Scientific Institute of Public Health ${ }^{(36)}$.

The present study targeted adults aged 25-64 years because, roughly considered, these are the active years in an average lifetime, when both psychological well-being ${ }^{(37-39)}$ and $\mathrm{PA}^{(40,46,48)}$ can represent areas of concern. Consequently, participants in the present study were 6803 adults aged 25-64 years (3368 men; 3435 women). Table 1 presents characteristics of the sample in terms of socio-economic status (SES) and PA. The protocol of the B-HIS was approved by the Ethical Committee of the Belgian Scientific Institute of Public Health.

\section{Instruments and data analysis}

The B-HIS included three parts: a household form, a faceto-face form and a written form. Instruments for each health-related domain were constructed following a strict protocol, including mainly standardised questionnaires from the WHO Consensus on Harmonizing Methods and Instruments for Health Surveys, the Dutch Central Bureau of Statistics, the Belgian Centre for Social Policy and the French National Institute for Health and Medical Research. Some questionnaires were adapted to the Belgian situation and all instruments were officially translated by the Scientific Institute of Public Health in the three Belgian official languages, Dutch, French and German ${ }^{(36)}$.

In the present study, PA was measured by the short International PA Questionnaire (IPAQ), last week version. This questionnaire was part of the face-to-face form. The IPAQ produced repeatable data (Spearman's rho clustered around 0.8) and is acknowledged as a valid measure for monitoring population levels of PA among adults aged $18-65$ years in diverse settings ${ }^{(41)}$. Participants reported days, hours and minutes of vigorous-intensity PA, moderate-intensity PA and walking during the last week. Total amounts of minutes spent in each of these activities were computed. The data were strongly right skewed and logistic transformation did not help obtaining valid results with continuous data. This phenomenon occurs frequently in the field of PA, and the common approach for handling this problem is dichotomisation. Although disapproved by many, dichotomisation produces meaningful findings that are easily understandable to a wide audience; and measures of association for dichotomous 
variables (e.g. the OR) have many advantages, and are often more realistic and meaningful measures of strength of a relationship than the product-moment correlation, $r^{(42)}$. In addition to the advantage of efficient data interpretation, the present study used powerful statistical tests (i.e. logistic regression) and a large enough sample to counteract the partial loss of variability caused by dichotomisation. Moreover, analyses on dichotomised and non-dichotomised data gave identical results. Cut-off points for dichotomisation were the numbers in the PA recommendations ${ }^{(1,2)}$. As presented in Table 1, we obtained three PA variables, with two levels each (e.g. Recommended Vigorous PA: 'Yes' and 'No'). Walking was the lightest-intensity PA in our study.

We created five MH variables using the General Health Questionnaire-12 (GHQ12) and the Symptom Check-List90-Revised (SCL-90-R). Official translations of these questionnaires ${ }^{(36,54,55)}$ were part of the face-to-face form of the B-HIS. It is important to highlight that we arbitrarily named these variables 'dimensions' of MH. Undoubtedly, MH cannot be reduced to these elements, and differential diagnosis cannot be made by means of these questionnaires. $\mathrm{MH}$ is a vast and complex domain, which reaches far beyond symptoms, disorders and diagnoses. We regarded these $\mathrm{MH}$ variables as expressions of an emotionally and functionally disturbing load that distressing thoughts, feelings and sensations create in the general population.

The GHQ12 is a well-established screening instrument designed to detect possible non-psychotic psychiatric morbidity in community settings ${ }^{(43)}$. Its twelve questions ask participants to rate their feelings and behaviour on a 4-point response scale from 'not-at-all to 'much-morethan-usuat. We used the bimodal scoring method (i.e. 0-0$1-1)$, as the authors recommended ${ }^{(43)}$. Hence, sum scores ranged between 0 and 12, with higher scores indicating more psychological distress. Cronbach's alpha for the twelve items of the GHQ12 was 0.881 in our sample. We created the variable emotional well-being by reversing GHQ12 sum scores and dichotomising them by the median value (i.e. more psychological distress became less emotional well-being). Table 2 presents numbers of participants corresponding to each level of this variable.

The SCL-90-R is a widely used, fairly valid and reliable self-report symptom inventory that provides an overview of a person's symptoms and their intensity at a specific point in time ${ }^{(49)}$ (i.e. in the last week). The present study used forty-two items: seventeen items for feelings of depression, ten items for feelings of anxiety, twelve items for symptoms of somatisation and three items for sleeping problems. Answer categories were on a 5-point Likert scale, ranging from zero ('not at all) to four ('extremely'), with higher scores indicating more psychological complaints. Cronbach's alpha for the forty-two items of the SCL-90-R was 0.963 in our sample. Four distinct indicators for depression, anxiety, somatisation, and sleeping problems
Table 2 Characteristics of the sample regarding mental health

\begin{tabular}{|c|c|c|c|c|c|c|}
\hline \multirow[b]{2}{*}{ Mental health } & \multicolumn{2}{|c|}{ Men } & \multicolumn{2}{|c|}{ Women } & \multicolumn{2}{|c|}{ Total sample } \\
\hline & $n$ & $\%$ & $n$ & $\%$ & $n$ & $\%$ \\
\hline & 3368 & $49 \cdot 5$ & 3435 & $50 \cdot 5$ & 6803 & 100 \\
\hline \multicolumn{7}{|c|}{ Emotional well-being } \\
\hline More & 1416 & 45 & 1196 & 37 & 2612 & 42 \\
\hline Less & 1683 & 55 & 2045 & 63 & 3728 & 58 \\
\hline \multicolumn{7}{|c|}{ Feelings of depression } \\
\hline No & 2868 & 94 & 2816 & 89 & 5684 & 91 \\
\hline Yes & 174 & 6 & 345 & 11 & 519 & g \\
\hline \multicolumn{7}{|c|}{ Feelings of anxiety } \\
\hline No & 2903 & 95 & 2896 & 91 & 5799 & 93 \\
\hline Yes & 133 & 5 & 261 & 9 & 394 & 7 \\
\hline \multicolumn{7}{|c|}{ Symptoms of somatistion } \\
\hline No & 2901 & 95 & 2861 & 91 & 5762 & 93 \\
\hline Yes & 146 & 5 & 296 & 9 & 442 & 7 \\
\hline \multicolumn{7}{|c|}{ Sleeping problems } \\
\hline No & 2505 & 82 & 2477 & 78 & 4982 & 80 \\
\hline Yes & 530 & 18 & 679 & 22 & 1209 & 20 \\
\hline
\end{tabular}

were calculated by summing respondents' scores to the subscale items and then dividing them by the number of items in each subscale. Mean values for each subscale were then dichotomised at the threshold value of $2+$ (i.e. values $0-1$ were recoded as specific disorder-related symptoms ' $N o$ ', and values 2, 3, 4 were recoded as specific disorder-related symptoms ' Yes'). Numbers of participants corresponding to each level of these $\mathrm{MH}$ variables are listed in Table 2. Although the least favourable class of scores in the 'Yes' rows probably gathered most participants with diagnosed or diagnosable disorders, we emphasise again that these specific $\mathrm{MH}$ variables regarded feelings of depression and anxiety, symptoms of somatisation and indications of sleeping problems in the general population. We are aware that proper diagnosis cannot be based solely on these subscale scores.

MH is a complicated issue. Anxiety, displeasure, worries and other negative emotions are generally found in the population, and they are also present in several psychiatric conditions. Moreover, double diagnoses are common in clinical context, especially in the case of anxiety and depression, which were estimated to overlap in $40 \%$ of cases ${ }^{(50)}$. Hence, Dobson ${ }^{(51)}$ reasoned that the distinction between anxiety and depression is more conceptually satisfying than empirically provable. Given the frequent overlap in $\mathrm{MH}$, we were not surprised to find a moderate correlation between our measures of anxiety and depression (Spearman's rho $=0 \cdot 6$ ). Correlations between the other MH measures were rather weak (Spearman's rho, between $0 \cdot 2$ and $0 \cdot 4$ ). Nevertheless, each $\mathrm{MH}$ variable that we created had a distinct contribution to our study, given our objective to create a more differentiated picture about the PA-MH relationship.

First, through multiple logistic regression analyses, we attempted to explain each of the five dependent $\mathrm{MH}$ variables through the independent PA variables. Separate models were used in the total sample (controlling for gender, age and SES), and in the subsamples of women 
Table 3 Associations between three physical activities differing in intensity and five dimensions of mental health in men and women

\begin{tabular}{|c|c|c|c|c|c|c|c|}
\hline \multirow[b]{2}{*}{ Mental health } & \multirow[b]{2}{*}{ PA } & \multicolumn{3}{|c|}{ Men ( $n$ 3368) } & \multicolumn{3}{|c|}{ Women (n 3435) } \\
\hline & & $P$ & OR & $95 \% \mathrm{Cl}$ & $P$ & OR & $95 \% \mathrm{Cl}$ \\
\hline Emotional well-being & $\begin{array}{l}\text { Vigorous PA } \\
\text { Moderate PA } \\
\text { Walking }\end{array}$ & $\begin{array}{l}0 \cdot 465 \\
0 \cdot 311 \\
0 \cdot 125\end{array}$ & $\begin{array}{l}1 \cdot 058 \\
1 \cdot 083 \\
1 \cdot 121\end{array}$ & $\begin{array}{l}0.909,1.232 \\
0.929,1.263 \\
0.969,1.298\end{array}$ & $\begin{array}{l}0.805 \\
0.230 \\
\mathbf{0 . 0 1}\end{array}$ & $\begin{array}{l}1 \cdot 022 \\
1.101 \\
1 \cdot 202\end{array}$ & $\begin{array}{l}0.860,1 \cdot 214 \\
0.941,1 \cdot 289 \\
\mathbf{1 . 0 3 8}, \mathbf{1} \cdot 394\end{array}$ \\
\hline Feelings of depression & $\begin{array}{l}\text { Vigorous PA } \\
\text { Moderate PA } \\
\text { Walking }\end{array}$ & $\begin{array}{l}0.003 \\
0.03 \\
0.356\end{array}$ & $\begin{array}{l}0.580 \\
0.677 \\
0.863\end{array}$ & $\begin{array}{l}\mathbf{0} \cdot 405, \mathbf{0 . 8 3 0} \\
\mathbf{0} \cdot 472,0.970 \\
0.631,1 \cdot 180\end{array}$ & $\begin{array}{l}0.093 \\
0.498 \\
0.272\end{array}$ & $\begin{array}{l}0.780 \\
0.916 \\
0.880\end{array}$ & $\begin{array}{l}0.584,1 \cdot 042 \\
0.712,1 \cdot 180 \\
0.700,1 \cdot 106\end{array}$ \\
\hline Feelings of anxiety & $\begin{array}{l}\text { Vigorous PA } \\
\text { Moderate PA } \\
\text { Walking }\end{array}$ & $\begin{array}{l}\mathbf{0 . 0 0 4} \\
0.132 \\
0.638\end{array}$ & $\begin{array}{l}\mathbf{0 . 5 4 7} \\
0.733 \\
0.918\end{array}$ & $\begin{array}{l}\mathbf{0 . 3 6 4}, \mathbf{0 . 8 2 1} \\
0.490,1.098 \\
0.644,1.310\end{array}$ & $\begin{array}{l}0.253 \\
0.358 \\
0.623\end{array}$ & $\begin{array}{l}0.827 \\
0.874 \\
0.937\end{array}$ & $\begin{array}{l}0.598,1 \cdot 145 \\
0 \cdot 655,1 \cdot 165 \\
0.723,1 \cdot 214\end{array}$ \\
\hline Symptoms of somatisation & $\begin{array}{l}\text { Vigorous PA } \\
\text { Moderate PA } \\
\text { Walking }\end{array}$ & $\begin{array}{l}\mathbf{0 . 0 0 9} \\
0 \cdot 074 \\
0.241\end{array}$ & $\begin{array}{l}\mathbf{0 . 5 9 0} \\
0 \cdot 700 \\
0.816\end{array}$ & $\begin{array}{l}\mathbf{0 . 3 9 8}, \mathbf{0 . 8 7 4} \\
0.473,1.035 \\
0.581,1.146\end{array}$ & $\begin{array}{l}0.120 \\
0.03 \\
0.172\end{array}$ & $\begin{array}{l}0.776 \\
0.737 \\
0.843\end{array}$ & $\begin{array}{l}0.564,1.068 \\
0.556,0.977 \\
0.659,1.077\end{array}$ \\
\hline Sleeping problems & $\begin{array}{l}\text { Vigorous PA } \\
\text { Moderate PA } \\
\text { Walking }\end{array}$ & $\begin{array}{l}0.653 \\
0.206 \\
0.598\end{array}$ & $\begin{array}{l}0.955 \\
0.875 \\
1.053\end{array}$ & $\begin{array}{l}0.779,1 \cdot 169 \\
0 \cdot 712,1.076 \\
0.868,1 \cdot 279\end{array}$ & $\begin{array}{l}0.700 \\
0.061 \\
0.221\end{array}$ & $\begin{array}{l}0.960 \\
0.832 \\
1 \cdot 116\end{array}$ & $\begin{array}{l}0.778,1.184 \\
0.687,1.008 \\
0.936,1.332\end{array}$ \\
\hline
\end{tabular}

PA, physical activities.

OR, $95 \% \mathrm{Cl}$ and associated significance levels are reported, and significant results are highlighted in bold.

and men (controlling for age and SES). Second, in order to be sure that we did not lose too much information due to dichotomisation, and in order to supply more detail to our results, we created two combined-symptom variables with three score categories Emotional well-being and Psychological complaints, by dividing GHQ12 and SCL-90-R sum scores in tertiles (i.e. high, medium and low). New sets of multiple logistic regression analyses were conducted separately in women and men, in which we attempted to explain differences in Emotional well-being and in Psychological complaints between each pair of tertiles through the independent PA variables.

We used the Statistical Package for Social Sciences statistical software package version 15 (SPSS Inc., Chicago, IL, USA) for all analyses.

\section{Results}

Because the initial results in the total sample were in later analyses replicated exclusively in women or in men, we reported only results of the gender-specific analyses. As presented in Table 3, our results suggested that in our sample, clearly different intensity levels characterised the PA that associated with $\mathrm{MH}$ in women and men. In men, inverse associations were found between participation in vigorous PA at recommended levels and above and feelings of depression $(\mathrm{OR}=0.580 ; 95 \%$ CI 0.405, 0.830), anxiety $(\mathrm{OR}=0.547 ; 95 \%$ CI $0.364,0.821)$ and symptoms of somatisation (OR $=0.590 ; 95 \%$ CI 0.398, 0.874), and between participation in moderate $\mathrm{PA}$ at recommended levels and above and feelings of depression $(\mathrm{OR}=0 \cdot 677$; $95 \%$ CI 0.472, 0.970). In women, positive associations were found between walking at recommended levels and above and emotional well-being $(\mathrm{OR}=1 \cdot 202 ; 95 \%$ CI $1 \cdot 038$,
1.394), and inverse associations between participation in moderate PA at recommended levels and above and symptoms of somatisation (OR $=0.737 ; 95 \%$ CI 0.556, 0.977).

Our secondary analyses, including combined-symptom variables with three score categories for Emotional wellbeing and for Psychological complaints, supported all earlier findings. In men, we found no significant difference in Emotional well-being between tertiles for either PA, whereas differences in Psychological complaints were significant for vigorous PA between the two higher tertiles $(\mathrm{OR}=0.705 ; 95 \% \mathrm{CI} 0.577,0.861)$ and between the lowest and the highest tertiles (OR $=0 \cdot 786$; $95 \%$ CI 0.650, 0.950). In women, the difference in Emotional well-being between the two higher tertiles was significant for walking (OR $=1 \cdot 223 ; 95 \%$ CI 1.034, 1.446), and differences in Psychological complaints were significant for moderate PA between the two higher tertiles ( $\mathrm{OR}=0.779 ; 95 \% \mathrm{CI}$ $0.636,0.955)$, and between the lowest and the highest tertiles (OR $=0 \cdot 806 ; 95 \%$ CI 0.663, 0•980).

\section{Discussion}

The present study analysed associations between PA of three different intensities and five dimensions of $\mathrm{MH}$ - one general (emotional well-being) and four specific (related to depression, anxiety, somatisation and sleeping problems) - in a population-based sample of 3368 men and 3435 women, aged 25-64 years, from the Belgian Health Interview Survey. We aimed to provide detailed and gender-specific insight regarding the $\mathrm{PA}-\mathrm{MH}$ relationship, with the objective to create a more differentiated picture about this complex relationship.

In the general population, the associations found between PA and MH were always positive, regardless of 
activity intensity. Hence, in all significant associations, all PA types were either positively associated with Emotional well-being, or inversely associated with Psychological complaints, represented by feelings of depression and anxiety, or symptoms of somatisation. No significant inverse associations were found between PA and $\mathrm{MH}$, not even in the case of vigorous PA, about which earlier studies suggested that it could lead to deleterious effects on $\mathrm{MH}$, particularly in women ${ }^{(20-23)}$. Our results indicated that the positive associations between vigorous PA and $\mathrm{MH}$ manifest in men rather than in women; however, no positive association was found between vigorous PA and $\mathrm{MH}$ problems in women. Our results support earlier findings suggesting that psychologically, men are more likely to benefit from vigorous activities, whereas women from lighter ones ${ }^{(35,44)}$. Hence, among women, we found positive associations between $\mathrm{MH}$ and participation in the two milder-intensity PA types in our study (i.e. walking and types moderate PA).

Further, our results suggested that the positive associations between PA and $\mathrm{MH}$ in men referred to vigorous PA and to Psychological complaints (i.e. specific dimensions of $\mathrm{MH}$ ). In contrast, the positive associations between PA and $\mathrm{MH}$ in women referred to walking and moderate PA and to both Emotional well-being and Psychological complaints (i.e. general and specific dimensions of $\mathrm{MH}$ ). These findings might strengthen the empirical knowledge for preventive population measures and health promotion. In men, the positive $\mathrm{PA}-\mathrm{MH}$ relationship addresses symptoms, namely palpable discomfort (i.e. men's complaints) and the optimal PA intensity is high. In women, the positive PA-MH relationship addresses complaints, but also distress, namely women's lowered mood, disturbing anxiety and altered well-being, and the optimal PA intensity is mild.

Our finding of a positive association between walking and $\mathrm{MH}$ exclusive to women is in line with earlier findings suggesting that it is significantly more likely in women than in men that enhanced psychological wellbeing will follow from walking ${ }^{(45)}$. Explanation for this might be that walking not only represents a milder form of PA, probably the most accessible one, which seldom requires special equipment or expenses, and it can easily be incorporated in everyday routines ${ }^{(47)}$, but walking also gives opportunities to observe things and reflect on matters that otherwise may get lost in the pressure of daily living. This creates fertile ground for internal balance. Moreover, when walking is a shared experience, it provides opportunities for social interaction and bonding. It might be more important in women than in men that such extra stimuli accompany PA when targeting psychological benefits.

Given the cross-sectional design of our study, we cannot talk about the beneficial effects of walking on $\mathrm{MH}$ in women. For all we know, higher emotional well-being could result in greater likeliness of walking. It is not doubtable, however, that a positive relationship exists between walking and emotional well-being in women, which is absent in men. Furthermore, as the results of our secondary analyses showed, the significant difference in Emotional well-being associated with walking in women existed between the two higher tertiles, and not between the lowest and the highest tertiles, as one might have expected. Worth noted also that within the medium and the lowest tertiles, equal percentages of women reported participation in walking at recommended levels and above (i.e. $55 \%$ ), which were just slightly smaller than the corresponding percentage within the highest tertiles (i.e. $60 \%$ ). This could suggest a plus of joy associated with walking among women who rated their emotional wellbeing at least at a neither too high, nor too low level. Supposedly, it could be beneficial to raise awareness and enthusiasm regarding the relationship between walking and emotional well-being, and encourage this PA at population level, especially among women.

Consequently, in our sample, the positive PA-MH relationship displayed variations across PA intensity levels, dimensions of $\mathrm{MH}$ and in women and men. These variations were clear and supported by the results of both the preliminary and the secondary analyses. Hence, we consider that gender-specific PA recommendations specifically developed for $\mathrm{MH}$ would be beneficial. More focused health promotion efforts could be more successful; thus, acknowledging that a fine-tuned description of PA is necessary in relation with $\mathrm{MH}$ is essential. It is rather difficult to develop individualised PA recommendations at population level; however, it is doable to address women and men separately.

Despite realistic value being attachable to the issues addressed in the present paper, we must acknowledge certain shortcomings. The self-report nature of our data certainly represents a limitation of the present study. The issues of social desirability bias and recalls are definite cons of these instruments; however, they also have the ability to collect data from a large number of people at low costs, which are undeniable advantages ${ }^{(52)}$. Another limitation is that we did not control for pain or other physical restrictions in the analyses, but the greatest limitation of our study lies in its cross-sectional nature. Hence, it is not possible to ascertain the direction of causality in the associations. This is an old problem in the PA-MH field, which prompted Rejeski ${ }^{(53)}$ to question the potential of scientific research to ever move from description to prescription of $\mathrm{PA}$ in relation with $\mathrm{MH}$. Reasons for this doubt are rooted in the complexity of the PA-MH relationship, and in the fact that a dose-response relationship has heuristic value in relation with the physiology of PA, but it fails to account for the cognitive and emotional experiences of the individual who performs PA. $\mathrm{MH}$ is complicated; thus, the $\mathrm{PA}-\mathrm{MH}$ relationship cannot be simple. Nevertheless, by structuring its complexity, by remembering that it varies across PA domains, 
MH dimensions and among different individuals, especially among women and men, we can get closer to use this significant positive relationship to the benefit of every individual.

\section{Acknowledgements}

We deeply appreciate the work and support of the members of the Epidemiology Unit at the Scientific Institute of Public Health in Brussels (Belgium). Special thanks to Lydia Gisle and Jean Tafforeau. Source of funding: The present study was supported by a grant from Ghent University. Conflicts of interest: There are no conflicts of interest, financial or of any other kind, for the authors of this paper. Authors' contribution: M.A. contributed with conception and design, data analysis and interpretation, and wrote the manuscript; I.D.B. and G.C. contributed with conception and design, and have provided feedback and guidance throughout the study.

\section{References}

1. Haskell WL, Lee I-M, Pate RR et al. (2007) Physical activity and public health: updated recommendation for adults from the American College of Sports Medicine and the American Heart Association. Circulation 116, 1081-1093.

2. Centers for Disease Control and Prevention (2000) Compliance with physical activity recommendations by walking for exercise. Morb Mortal Wkly Rep 49, 560-565.

3. Scully D, Kremer J, Meade MM et al. (1998) Physical exercise and psychological well-being: a critical review. Br J Sports Med 32, 111-120.

4. Landers M (2009) The influence of exercise on mental health. The President's Council on Physical Fitness and Sports Research Digest, originally published as Series 2, no. 12. http://www.fitness.gov/mentalhealth.html (accessed November 2008).

5. Fox KR (1999) The influence of physical activity on mental well-being. Public Health Nutr 2, 411-418.

6. Biddle SJH, Fox KR \& Boutcher SH (2000) Physical Activity and Psychological Well-being, 1st ed., pp. 1-88. Oxon: Routledge.

7. Jones M \& O'Beney C (2004) Promoting mental health through physical activity: examples from practice. $J$ Ment Health Promot 3, 39-47.

8. World Health Organization (1995) Exercise for health. WHO/FIMS Committee on physical activity for health. Bull World Health Organ 73, 135-136.

9. Hill JW (1987) Exercise prescription. Prim Care 14, 817-825.

10. Berger BG \& McInman A (1993) Exercise and the quality of life. In Handbook of Research on Sport Psychology, pp. 729-760 [RN Springer, M Murphy and LK Tennant, editors]. New York: Macmillan.

11. Nieman P (2002) Psychosocial aspects of physical activity. Paediatr Child Health 7, 309-312.

12. Seraganian P (1993) Exercise Psychology. New York: John Wiley \& Sons.

13. Vuillemin A, Boini S, Bertrais S et al. (2005) Leisure time physical activity and health-related quality of life. Prev Med 41, 562-569.

14. Wijndaele K, Matton L, Duvigneaud N et al. (2007) Associations between leisure time physical activity and stress, social support and coping: a cluster-analytical approach. Psychol Sport Exerc 8, 425-440.

15. Gauvin L \& Spence JC (1996) Physical activity and psychological well-being: knowledge base, current issues, and caveats. Nutr Rev 54, 4 Pt 2, S53-S65.

16. US Department of Health and Human Services, Center for Chronic Disease Prevention and Health Promotion (1999) Physical activity and health. A report of the Surgeon General. Chapter 4: Physical activity and mental health. http://www.cdc.gov/nccdphp/sgr/pdf/chap4.pdf (accessed February 2008).

17. Craft LL (1997) The effect of exercise on clinical depression and depression resulting from mental illness: a metaanalysis. J Sport Exerc Psychol 20, 339-357.

18. Raglin JS (1997) Anxiolytic effects of physical activity. In Physical Activity and Mental Health, pp. 107-126 [WP Morgan, editor]. Washington, DC: Taylor \& Francis.

19. Cox RH, Thomas TR, Hinton PS et al. (2004) Effects of acute 60 and $80 \% \mathrm{VO}_{2}$ max bouts of aerobic exercise of state anxiety of women of different age groups across time. Res Q Exerc Sport 75, 165-175.

20. Raglin JS, Wilson GS \& Galper D (2007) Exercise and its effects on mental health. In Physical Activity and Health, pp. 247-259 [C Bouchard, SN Blair and WL Haskell, editors]. Campaign, IL: Human Kinetics Inc.

21. Bouchard C, Shephard RJ \& Stephens T (1994) Physical Activity, Fitness, and Health: International Proceedings and Consensus Statement, pp. 851-897. Chicago, IL: Human Kinetics.

22. Home T (1994) Predictors of physical activity intentions and behaviour for rural homemakers. Can J Public Health 85, 132-135.

23. Anderson DF, Broom EF \& Pooley JC (1995) Foundations of Canadian Physical Education. Recreation and Sports Studies. Madison, WI: WCB Brown \& Benchmark Publications.

24. Ford ES, Merritt RK, Heath GW et al. (1991) Physical activity in lower and higher socioeconomic status population. $\mathrm{AmJ}$ Epidemiol 133, 1246-1256.

25. Farrell PA, Gustafson AB, Morgan WP et al. (1987) Enkefhalins, catecholamins and psychological mood alterations: effects of prolonged exercise. Med Sci Sports Exerc 19, 347-353.

26. Steptoe A \& Cox S (1988) The acute effects of aerobic exercise on mood: a controlled study. Health Psychol 7, 329-340.

27. Berger BG \& Motl RW (2000) Exercise and mood: a selective review and synthesis of research employing the Profile of Mood States. J Appl Sport Psychol 12, 69-92.

28. Moses J, Steptoe A, Mathews A et al. (1989) The effects of exercise training on mental well-being in the normal population: a controlled trial. J Psychosom Res 33, 47-61.

29. Stewart AL, King AC \& Haskell WL (1993) Endurance exercise and health-related quality of life outcomes in 50-65 year old adults. Gerontologist 33, 782-789.

30. Morgan WP (1997) Physical Activity and Mental Health, pp. 58-60. Bristol: Taylor \& Francis.

31. Martinsen EW, Hoffart A \& Solberg O (1998) Aerobic and non-aerobic forms of exercise in the treatment of anxiety disorders. Stress Med 5, 115-120.

32. Cox RH, Thomas TR \& Davis JE (2000) Delayed anxiolytic effect associated with an acute bout of aerobic exercise. J Exerc Physiol 3, 59-66.

33. Petruzzello SJ, Landers DM, Hatfield BD et al. (1991) A meta-analysis on the anxiety-reducing effects of acute and chronic exercise. Sports Med 11, 143-182.

34. Stephens T (1988) Physical activity and mental health in the United States and Canada: evidence from four population surveys. Prev Med 17, 35-47.

35. Brown DR, Wang Y, Ward A et al. (1995) Chronic psychological effects of exercise and exercise plus cognitive strategies. Med Sci Sports 27, 765-775. 
36. Scientific Institute of Public Health, Epidemiology Unit (date unknown) Health Interview Survey in Belgium. http://www.iph.fgov.be/epidemio/epien/index4.htm (accessed October 2006). Full reports 2001, 2004 available in Dutch or French at http://www.iph.fgov.be/EPIDEMIO/ epinl/crospnl/hisnl/table01.htm, http://www.iph.fgov.be/ EPIDEMIO/EPINL/crospnl/hisnl/table04.htm (accessed November 2008).

37. Economic and Social Research Council (2008) Mental Health and mental illness in the UK. Fact Sheet. http://www. esrcsocietytoday.ac.uk/ESRCInfoCentre/facts/UK/index 56. aspx?ComponentId=12917\&SourcePageId=18133\#footnote (accessed December 2008).

38. Huyck MH (1993) Middle age. Academic American Encyclopedia 13, 390-391.

39. Trollor JT, Anderson TM, Sachdev P et al. (2007) Prevalence of mental disorders in the elderly: the Australian National Mental Health and Well-being Survey. Am J Geriatr Psychiatry 15, 455-466.

40. De Bourdeaudhuij I, Van Oost P \& Mommerency G (1994) Psychological Determinants of Leisure Time Physical Activity in Adolescents and Adults. Research Report. Ghent: Ghent University.

41. Craig CL, Marshall AL, Sjostrom M et al. (2003) International Physical Activity Questionnaire: 12-country reliability and validity. Med Sci Sports Exerc 35, 1381-1395.

42. Farrington DP \& Loeber R (2006) Some benefits of dichotomization in psychiatric and criminological research. Crim Behav Ment Health 10, 100-122.

43. Goldberg DP \& Williams P (1988) A Users Guide to the General Health Questionnaire. Windsor: Nfer Nelson.

44. Sandlund ES \& Norlander T (2000) The effects of Tai Chi Chuan relaxation and exercise on stress responses and well-being: an overview of research. Int J Stress Manag 7, 139-149.

45. Ransford HE \& Bartolomeo JP (1996) Aerobic exercise, subjective health and psychological wellbeing within age and gender subgroups. Soc Sci Med 42, 1555-1559.
46. Borodulin K, Laatikainen T, Juolevi A et al. (2008) Thirtyyear trends of physical activity in relation to age, calendar time and birth cohort in Finnish adults. EurJ Public Health 18, 339-344.

47. Heart Foundation (2008) Walking. Fact Sheet, 16 August. http://74.125.77.132/search?q= cache:IUQSYgixcGIJ:www. heartfoundation.org.au/document/NHF/HL_walking_factsheet final_16\%252008\%252007.pdf+walking + the + most + accessible + form + of + physical + activity\&hl $=$ en $\& \mathrm{ct}=\operatorname{clnk} \& \mathrm{~cd}=1$ (accessed December 2008).

48. Evenson KR, Wilcox S, Pettinger M et al. (2002) Vigorous leisure activity through women's adult life: the Women's Health Initiative Observational Cohort Study. Am J Epidemiol 156, 945-953.

49. Derogatis LR (1977) SCL: Administration, Scoring and Procedures. Manual II. Baltimore, MD: John Hopkins University School of Medicine, Clinical Psychometrics Research Unit.

50. Croft H (2008) The Line between Anxiety and Depression. Healthy Place Articles. http://www.healthyplace.com/anxietypanic/insights-into-anxiety/line-between-anxiety-and-depression/ menu-id-1233/ (accessed January 2009).

51. Dobson KS (1985) The relationship between anxiety and depression. Clin Psychol Rev 5, 307-324.

52. Sallis JF \& Saelens BE (2000) Assessment of physical activity by self-report: status, limitations, and future directions. Res Q Exerc Sport 71, S1-S14.

53. Rejeski WJ (1994) Dose-response issues from a psychosocial perspective. In Physical Activity, Fitness, and Health: International Proceedings and Consensus Statement, pp. 851-897 [C Bouchard, RJ Shephard and T Stephens, editors]. Chicago, IL: Human Kinetics.

54. Arrindell WA \& Ettema JHM (1986) SCL-90: Handleiding bij een multidimensionele psychopathologieindicator. Lisse: Swets \& Zeitlinger, Test Services.

55. Koeter MWJ \& Ormel J (1991) General Health Questionnaire, Nederlandse bewerking: Handleiding. Lisse: Swets \& Zeitlinger, Test Services. 